Ophthalmologica

\title{
Osteopontin and 'Melanoma Inhibitory Activity': Comparison of Two Serological Tumor Markers in Metastatic Uveal Melanoma Patients
}

\author{
Ingrid Haritoglou ${ }^{\mathrm{a}}$ Armin Wolf $^{\mathrm{a}}$ Tanja Maier $^{\mathrm{b}}$ Christos Haritoglou ${ }^{\mathrm{a}}$ \\ Rüdiger Hein ${ }^{c}$ Ulrich Christoph Schaller ${ }^{\mathrm{a}}$ \\ a Department of Ophthalmology and bepartment of Dermatology, Ludwig Maximilians University, and \\ 'Department of Dermatology, Technical University, Munich, Germany
}

\section{Key Words}

Uveal melanoma $\cdot$ Metastases $\cdot$ Osteopontin $\cdot$ Melanoma

inhibitory activity $\cdot$ Serological marker

\begin{abstract}
Background: Evaluation of the protein osteopontin (OPN) as a potential new marker in comparison to melanoma inhibitory activity (MIA) for screening and detection of metastatic uveal melanoma. Methods: Plasma levels of 32 patients with uveal melanoma were analyzed for OPN and MIA by enzyme-linked immunosorbent assay (ELISA). Fourteen of these patients had clinically detectable liver metastases. Results: Median plasma concentration of OPN in patients with metastatic disease was $152.01 \mathrm{ng} / \mathrm{ml}$ compared to 47.39 $\mathrm{ng} / \mathrm{ml}$ in patients without clinically detectable metastases $(p<0.001)$. The difference between the median MIA plasma levels in patients with $(13.11 \mathrm{ng} / \mathrm{ml})$ and patients without $(5.64 \mathrm{ng} / \mathrm{ml})$ metastatic disease was also statistically significant $(p<0.001)$. No correlation could be found between MIA or OPN levels and tumor height in patients without clinically detectable metastases. Conclusion: The proteins MIA and OPN seem to be promising tumor markers for the metastasis screening in patients with uveal melanoma.
\end{abstract}

Copyright $\odot 2009$ S. Karger AG, Basel

\section{Introduction}

Uveal melanoma is the most common primary malignant intraocular tumor in adults. The 5-, 10- and 15-year survival rates based on tumor-related mortality are reported to be 72,59 and 53\%, respectively. Uveal melanoma typically metastasizes to the liver. Following the diagnosis of metastatic disease, the median time of survival decreases to less than 1 year $[1,2]$. An appropriate screening for early detection of metastatic disease is essential in order to lower melanoma-related mortality [3].

The Collaborative Ocular Melanoma Study Group (COMS) recommends a semiannual evaluation of liver function tests as screening tool for metastatic disease [4]. In case of suspected metastatic disease abdominal ultrasonography is recommended as an initial examination in addition to chest radiography to rule out metastases from lung cancer to the eye $[1,5]$. Besides these examinations, a sensitive and specific serological marker for the early detection of metastatic disease would be of great value.

Two promising proteins have recently been reported, namely 'melanoma inhibitory activity' (MIA) [6-8] and osteopontin (OPN) $[9,10]$. The latter is expressed by various cell types and its expression has been shown to enhance tumorigenicity and metastases [11], to lead to more

\section{KARGER}

Fax +41613061234 E-Mail karger@karger.ch www.karger.com (c) 2009 S. Karger AG, Basel $0030-3755 / 09 / 2234-0239 \$ 26.00 / 0$

Accessible online at: www.karger.com/oph
Ingrid Haritoglou

Department of Ophthalmology, Ludwig Maximilians University

Mathildenstrasse 8, DE-80336 Munich (Germany)

Tel. +49 895160 3811, Fax +498951605160

E-Mail Ingrid.Haritoglou@med.uni-muenchen.de 
aggressive tumor growth in various cancers [12] and to increase the invasive behavior of cutaneous melanoma cells [13].

This study was designed to compare OPN and MIA plasma levels in patients with uveal melanoma both with and without metastatic disease, and to evaluate the impact of tumor size on plasma levels of both proteins.

\section{Materials and Methods}

Thirty-three plasma samples of 32 patients with uveal melanoma were analyzed. OPN and MIA plasma levels were quantified by an enzyme-linked immunosorbent assay (ELISA). Fourteen of these patients had clinically proven metastases. In 1 of the 14 patients with metastatic disease two samples were available, one taken before and one after the development of clinically detectable metastases. Screening for metastatic disease was done by a tumor specialist by using liver ultrasound and liver enzymes (alkaline phosphates, AST, ALT and bilirubin) as well as chest Xray. Abnormal findings triggered the administration of a subsequent diagnostic test such as computed tomography (CT) scan, magnetic resonance imaging (MRI) or biopsy.

Sample collection was performed after written informed consent had been obtained. The study followed the principles expressed in the Declaration of Helsinki and had been approved by the local ethics committee. Data of these 32 patients were already partly used in previous studies [10].

Tumor height was measured by standardized echography using A-scan techniques described previously [14] at the time when blood samples were obtained from the patients. According to the tumor height measured, patients without clinically detectable metastases were divided into the following three groups: small melanomas ( $\geq 3 \mathrm{~mm}$ ), medium-sized melanomas $(3-5 \mathrm{~mm})$ and large melanomas ( $\geq 5 \mathrm{~mm}$ ).

Plasma levels of OPN and MIA were both evaluated with an ELISA test kit (R\&D Systems, Minneapolis, Minn., USA and Roche, Mannheim, Germany, respectively) according to the manufacturer's instructions. The reliability and reproducibility of both kits have previously been described in the literature $[9,15]$. The blood samples for the examinations of both markers were drawn from the same patients. Statistical analysis was performed using the Mann-Whitney U test, Wilcoxon test and Kruskal-Wallis test. Data were collected and analyzed using Microsoft Excel and SPSS 11.0 for Windows.

\section{Results}

Seventeen (53\%) of the 32 patients were female and 15 (47\%) patients were male. Patients' age varied from 37 to 81 years (median 58 years). Patients without clinically detectable metastases had a median apical tumor height of $5.0 \mathrm{~mm}$. Six patients had small melanomas $(\leq 3 \mathrm{~mm}), 4$ patients had medium-sized melanomas $(3-5 \mathrm{~mm})$ and 8 patients had large melanomas ( $\geq 5 \mathrm{~mm}$ ) (table 1). The median apical tumor height in patients with clinically detectable metastases was $6.5 \mathrm{~mm}$.

Concerning therapy for the primary tumor in the group of patients without metastases, 15 of 18 patients had already been treated: 7 by ${ }^{106} \mathrm{Ru}$ plaque brachytherapy, 7 by irradiation using the gamma knife and 1 patient by enucleation. In the group of patients with metastatic disease, 12 of 14 patients had been treated for primary tumor: 5 were irradiated with the gamma knife and 1 with proton beam, 3 were treated with ${ }^{106} \mathrm{Ru}$ plaque brachytherapy, 2 patients received transpupillary thermotherapy ( 1 of them was later on enucleated because of tumor recurrence) and another patient was primarily enucleated.

The median plasma concentration of OPN in patients without clinically detectable metastases was $47.39 \mathrm{ng} / \mathrm{ml}$ (25th percentile: $37.69 \mathrm{ng} / \mathrm{ml}$; 75 th percentile: $75.49 \mathrm{ng} /$ $\mathrm{ml}$ ) (table 2). There was no statistically significant difference between plasma levels in patients with small, medium-sized or large melanoma in this study population ( $\mathrm{p}>0.2$, Kruskal-Wallis test) (table 1). The median OPN level in patients with metastatic uveal melanoma was $152.01 \mathrm{ng} / \mathrm{ml}$ (25th percentile: $87.52 \mathrm{ng} / \mathrm{ml}$; 75 th percentile: $233.45 \mathrm{ng} / \mathrm{ml}$ ). The difference between patients with and without clinically detectable metastases was statistically highly significant $(\mathrm{p}<0.001$, Mann-Whitney $\mathrm{U}$ test $)$ (fig. 1, table 2).

The median MIA level in patients without metastatic disease was $5.64 \mathrm{ng} / \mathrm{ml}$ (25th percentile: $4.63 \mathrm{ng} / \mathrm{ml}$; 75th percentile: $8.0 \mathrm{ng} / \mathrm{ml}$ ) (table 2). As for OPN, no correlation could be found between MIA level and tumor height in this group ( $p>0.7$, Kruskal-Wallis test) (table 1). The median MIA level for patients with metastatic disease was $13.11 \mathrm{ng} / \mathrm{ml}$ (25th percentile: $8.89 \mathrm{ng} / \mathrm{ml}$; 75th percentile: $37.05 \mathrm{ng} / \mathrm{ml}$ ). As for OPN, the difference between the MIA levels in patients with and without clinically detectable metastases was statistically significant $(\mathrm{p}<0.001$, Mann-Whitney U test) (fig. 1b, table 2).

In the patient with metastatic disease, in whom the levels of OPN and MIA could be measured before and after the development of metastases, the concentrations of OPN and MIA were 118.67 and $9.8 \mathrm{ng} / \mathrm{ml}$ before and 375.54 and $26.53 \mathrm{ng} / \mathrm{ml}$ after generalization, respectively ( $\mathrm{p}<0.001$, Wilcoxon test).

In general, a comparison between OPN or MIA plasma levels and tumor burden or stage of metastases was very difficult, because all 14 patients had diffuse liver metastases. The median time gap between diagnosis of metastases and sample collection was 3 months. 
Fig. 1. OPN (a) and MIA (b) plasma levels in patients with and without clinically detectable metastases. Patients with metastases show significantly higher OPN and MIA levels than those without metastatic disease $(p<0.001$, Mann-Whitney $U$ test).
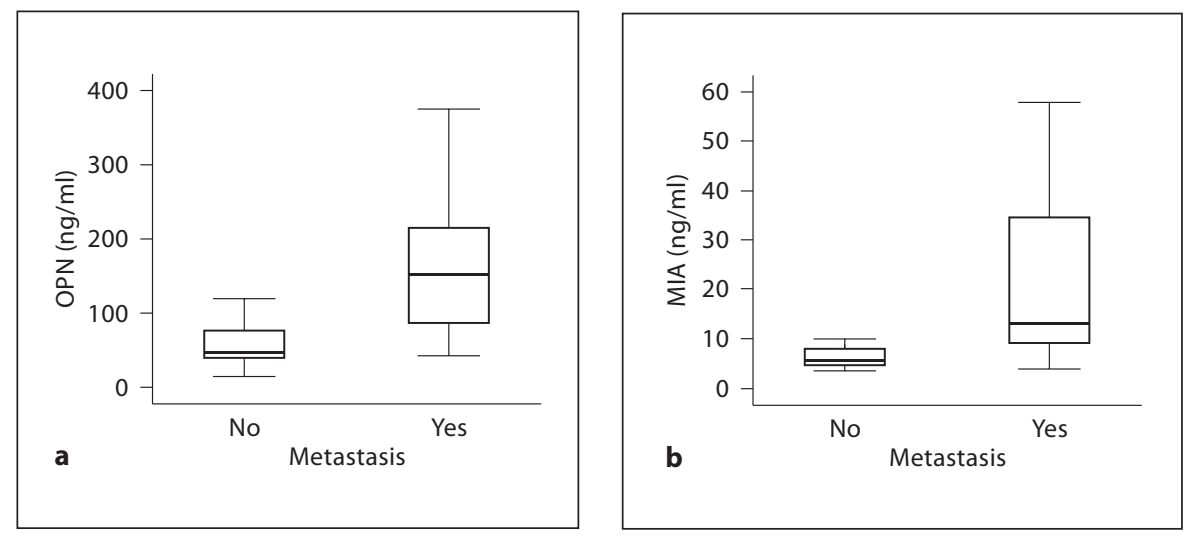

\section{Discussion}

There are several established parameters to identify patients at high risk of metastatic disease such as histological cell type, largest tumor diameter, tumor location and specific microcirculation patterns $[2,16]$. All these predictors of metastatic disease may help to indicate the risk of developing metastatic disease; they are, however, not able to detect metastatic disease itself.

The protein MIA, an attachment regulating protein, was already described as a tumor marker for cutaneous melanomas [15]. MIA specifically inhibits the attachment of melanoma cells to fibronectin and laminin and is therefore presumed to influence the detachment of melanoma cells from extracellular matrix. Therefore, MIA is considered to play an important role in the pathogenesis of metastases.

As in earlier studies [6-8] we were again able to demonstrate that elevated MIA plasma levels indicate metastatic disease also in the malignant melanoma of the uvea. These results have recently been confirmed by Barak et al. [17].

OPN is a 314 -amino acid phosphoglycoprotein that is a component of the noncollagenous bone matrix. OPN has been described in the context of diverse physiological roles such as chemotaxis, cell migration and adhesion, angiogenesis, apoptosis, cell-extracellular matrix interactions and immune regulation [18]. OPN actively promotes the tumorigenic phenotype and contributes to metastases. Increased OPN expression is associated with aggressive behavior and metastases in breast, colon, prostate, lung, liver and ovarian cancers [11]. OPN is secreted into the blood where it can be detected by ELISA. Elevated plasma levels have been observed in patients with advanced or metastatic cancers, including cutaneous mela-
Table 1. No statistically significant difference between plasma levels in patients with small, medium-sized or large melanomas could be seen for OPN and MIA in the group without clinically detectable metastases

\begin{tabular}{lllll}
\hline & \multicolumn{3}{c}{ Apical tumor thickness } & \multirow{2}{*}{$\mathrm{p}$} \\
\cline { 2 - 4 } & $\begin{array}{l}\leq 3 \mathrm{~mm} \\
(\mathrm{n}=6)\end{array}$ & $\begin{array}{l}3-5 \mathrm{~mm} \\
(\mathrm{n}=4)\end{array}$ & $\begin{array}{l}\geq 5 \mathrm{~mm} \\
(\mathrm{n}=8)\end{array}$ & \\
\hline OPN median, ng/ml & 43.22 & 44.59 & 60.13 & $>0.2$ \\
25th percentile & 26.65 & 42.36 & 40.85 & \\
75th percentile & 65.08 & 54.28 & 84.59 & \\
\hline MIA median, ng/ml & 6.31 & 6.49 & 5.16 & $>0.7$ \\
25th percentile & 4.84 & 3.25 & 4.28 & \\
75th percentile & 7.82 & 8.37 & 6.69 & \\
\hline
\end{tabular}

Table 2. OPN and MIA plasma levels in patients with and without clinically detectable metastases; the difference between these groups was statistically highly significant (Mann-Whitney $U$ test)

\begin{tabular}{lcrl}
\hline & \multicolumn{2}{c}{ Metastases } & \multirow{2}{*}{$\mathrm{p}$} \\
\cline { 2 - 3 } & no & yes & \\
\hline OPN median, ng/ml & 47.39 & 152.01 & $<0.001$ \\
25th percentile & 37.69 & 87.52 & \\
75th percentile & 75.49 & 233.45 & \\
\hline MIA median, ng/ml & 5.64 & 13.11 & $<0.001$ \\
25th percentile & 4.63 & 8.89 & \\
75th percentile & 8.0 & 37.05 & \\
\hline
\end{tabular}


noma $[12,13]$. Increased OPN plasma levels have recently also been described in patients with metastatic uveal melanoma $[9,10,17]$.

The present study was undertaken to compare plasma levels of MIA and OPN in patients with and without metastases from uveal melanoma and to assess a possible correlation between tumor height and MIA or OPN plasma levels in patients without clinically detectable metastases.

We found a significant difference between plasma levels in patients with and without clinically detectable metastases for both markers. As 1 patient in our study group developed metastases during the observation period, we were able to observe a marked increase for both MIA and OPN plasma levels along with the generalization of the tumor. This indicates that, in addition to the registration of single values of OPN or MIA plasma levels, the development or deviation from individual baseline values of these plasma levels over time should be taken into account $[6,7,19]$.

In the group of patients without clinically detectable metastases there was no statistically significant difference between the plasma levels both of MIA and OPN in patients with small, medium-sized or large melanomas. This confirms our previous results [6-8] and suggests that both markers are independent of tumor size. In all three groups the plasma levels of both markers were statistically similar to those in healthy control groups [15]. As described for other tumor markers in medicine, these results suggest that OPN and MIA are not adequate to diagnose or stage a primary tumor.

In order to evaluate the quality of a diagnostic test a receiver-operating-characteristic curve (ROC) would be of great value. In this analysis, the true-positive rate (sensitivity) is plotted against the false-positive rate (100 specificity) for different cutoff points. A test with perfect discrimination has an ROC plot that passes through the upper left corner (100\% sensitivity, 100\% specificity). Therefore the closer the ROC plot is to the upper left corner, the higher the overall accuracy of the test. Another parameter for the quality of a diagnostic test in this analysis is the area under the curve [20].

Recently, ROC curves were published for OPN and MIA [17]. Such an analysis must, however, be based on a larger amount of data: a minimum of 50 patients in each group should be included for a statistically relevant calculation [20]. We hope to give a valid calculation after inclusion of a larger number of patients into the current investigation.

In summary, OPN as well as MIA represent useful and cheap markers for the detection of metastatic disease and for the monitoring of patients with primary uveal melanoma. A low sensitivity of liver function testing $(60 \%$ for alkaline phosphates, $50 \%$ for AST and $40 \%$ for ALT) [17] as well as of abdominal ultrasonography and chest radiography [5] has already been demonstrated in the literature. Barak et al. [17] were able to demonstrate a considerably higher sensitivity and specificity of MIA and OPN, and that the combination of these two biomarkers was far superior to liver function testing. Therefore, it may be hypothesized that MIA and OPN could represent valuable tools even for the early detection of metastasis in these patients, if applied routinely.

The combination of both markers might increase the reliability of early detection giving our patients a chance for early intervention and prolonged survival. In the clinical practice, OPN and MIA plasma levels could be measured for instance 3-4 times per year instead of liver function testing. In case of abnormal levels, subsequent tests such as CT scan, MRI or biopsy could be performed.

In addition, MIA and OPN could play an important role in the monitoring of new treatment options for metastatic uveal melanoma.

\section{Acknowledgment}

This study was supported by a grant from the Kurt Bohnewands Fond.

\section{References}

1 Kivelä T, Eskelin S, Kujala E: Metastatic uveal melanoma. Int Ophthalmol Clin 2006;46: 133-149.

2 Mooy CM, De Jong PT: Prognostic parameters in uveal melanoma: a review. Surv Ophthalmol 1996;41:215-228.

3 Bedikian AY: Metastatic uveal melanoma therapy: current options. Int Ophthalmol Clin 2006;46:151-166.
4 Diener-West M, Reynolds SM, Agugliaro DJ, Caldwell R, Cumming K, Earle JD, Green DL, Hawkins BS, Hayman J, Jaiyesimi I, Kirkwood JM, Koh WJ, Robertson DM, Shaw JM, Thoma J: Screening for metastasis from choroidal melanoma: the Collaborative Ocular Melanoma Study Group Report 23. J Clin Oncol 2004;22:2438-2444. 
5 Eskelin S, Pyrhönen S, Summanen P, Prause JU, Kivelä T: Screening for metastatic malignant melanoma of the uvea revisited. Cancer 1999;85:1151-1159.

6 Reiniger IW, Schaller UC, Haritoglou C, Hein R, Bosserhoff AK, Kampik A, Mueller AJ: 'Melanoma inhibitory activity' (MIA): a promising serological tumour marker in metastatic uveal melanoma. Graefes Arch Clin Exp Ophthalmol 2005;243:1161-1166.

7 Schaller UC, Mueller AJ, Bosserhoff AK, Haraida S, Löhrs U, Buettner R, Kampik A: Melanoma inhibitory activity (MIA). Evaluation of a new tumor-associated antigen as a serum marker for uveal melanomas. Ophthalmologe 2000;97:429-432.

8 Schaller UC, Bosserhoff AK, Neubauer AS, Buettner R, Kampik A, Mueller AJ: Melanoma inhibitory activity: a novel serum marker for uveal melanoma. Melanoma Res 2002;12: 593-599.

9 Kadkol SS, Lin AY, Barak V, Kalickman I, Leach L, Valyi-Nagy K, Majumdar D, Setty S, Maniotis AJ, Folberg R, Pe'er J: Osteopontin expression and serum levels in metastatic uveal melanoma: a pilot study. Invest Ophthalmol Vis Sci 2006;47:802-806.
10 Reiniger IW, Wolf A, Welge-Lüssen U, Mueller AJ, Kampik A, Schaller UC: Osteopontin as a serologic marker for metastatic uveal melanoma: results of a pilot study. Am J Ophthalmol 2007;143:705-707.

11 Rittling SR, Chambers AF: Role of osteopontin in tumor progression. Br J Cancer 2004; 90:1877-1881.

12 Brown LF, Papadopoulos-Sergiou A, Berse B, Manseau EJ, Tognazzi K, Perruzzi CA, Dvorak HF, Senger DR: Osteopontin expression and distribution in human carcinomas. Am J Pathol 1994;145:610-623.

13 Zhou Y, Dai DL, Martinka M, Su M, Zhang Y, Campos EI, Dorocicz I, Tang L, Huntsman D, Nelson C, Ho V, Gang L: Osteopontin expression correlates with melanoma invasion. J Invest Dermatol 2005;124:1044-1052.

14 Ossoinig KC, Bigar F, Kaefring SL: Malignant melanoma of the choroid and ciliary body. A differential diagnosis in clinical echography. Bibl Ophthalmol 1975;83:141154 .
15 Bosserhoff AK, Kaufmann M, Kaluza B, Bartke I, Zirngibl H, Hein R, Stolz W, Buettner R: Melanoma-inhibiting activity, a novel serum marker for progression of malignant melanoma. Cancer Res 1997;57: 3149-3153.

16 Folberg R, Mehaffey M, Gardner LM, Meyer M, Rummelt V, Pe'er J: The microcirculation of choroidal and ciliary body melanomas. Eye 1997;11:227-238.

17 Barak V, Frenkel S, Kalickman I, Maniotis AJ, Folberg R, Pe'er J: Serum markers to detect metastatic uveal melanoma. Anticancer Res 2007;27:1897-1900.

18 Standal T, Borset M, Sundan A: Role of osteopontin in adhesion, migration, cell survival and bone remodeling. Exp Oncol 2004; 26:179-184

19 Stieber P, Heinemann V, Schalhorn A: Tumor markers - how they should be applied. MMW Fortschr Med 2005;147:35, 37-39.

20 Metz CE: Basic principles of ROC analysis. Semin Nucl Med 1978;8:283-298. 